\title{
Coefficient of Moment of Inertia for Ribbed RC Slab Beams
}

\author{
Šarūnas KELPŠA*, Gediminas RINKEVIČIUS**, Tadas ZINGAILA***, \\ Mindaugas AUGONIS ****, Vadimas KITOVAS $* * * * *$ \\ *Kaunas University of Technology, Studentu 48, 51367 Kaunas, Lithuania, E-mail: sarunas.kelpsa@ktu.lt \\ **UAB Kelprojektas, I. Kanto 25, LT-44296 Kaunas, Lithuania, E-mail: gediminas.rinkevicius@kelprojektasl.lt \\ ***Kaunas University of Technology, Studentu 48, 51367 Kaunas, Lithuania, E-mail: tadas.zingaila@ktu.lt \\ ****Kaunas University of Technology, Studentu 48, 51367 Kaunas, Lithuania, E-mail: mindaugas.augonis@ktu.lt \\ *****Peikko Lithuania, R. Kalantos 49, 52303 Kaunas, Lithuania, E-mail: vadimas.kitovas@peikko.com
}

crossref http://dx.doi.org/10.5755/j01.mech.25.3.22691

\section{Introduction}

Ribbed reinforced concrete slabs (Fig. 1) have been designed for many decades. Earlier, structural engineers used to evaluate internal forces of ribbed reinforced concrete slabs using analytical calculation methods which had implemented various assumptions for simplification purposes. The internal forces in slab members were calculated assuming that beams behave as absolutely rigid supports for the slabs. Meanwhile, in the design process of beams it was assumed that the columns or bearing walls are non-deforming supports [1]. However, the real structural behaviour of ribbed slabs is more complicated, where the slab members deform together with the connected beams, whereas the columns are not absolutely rigid supports. The settlement of different columns in the same structure can vary significantly depending on the characteristics of columns and soil under the foundations. This effect is especially relevant when analysing statically indeterminate structures, where analysis of the overall structural behaviour can lead to considerable differences of the estimated internal forces, compared to the results of simplified calculation methods. Application of design restrictions and safety factors in such cases allows design of safe structures [2, 3, 4]. However, the design process of optimal and cost-efficient structural solutions requires implementation of more advanced analysis methods.

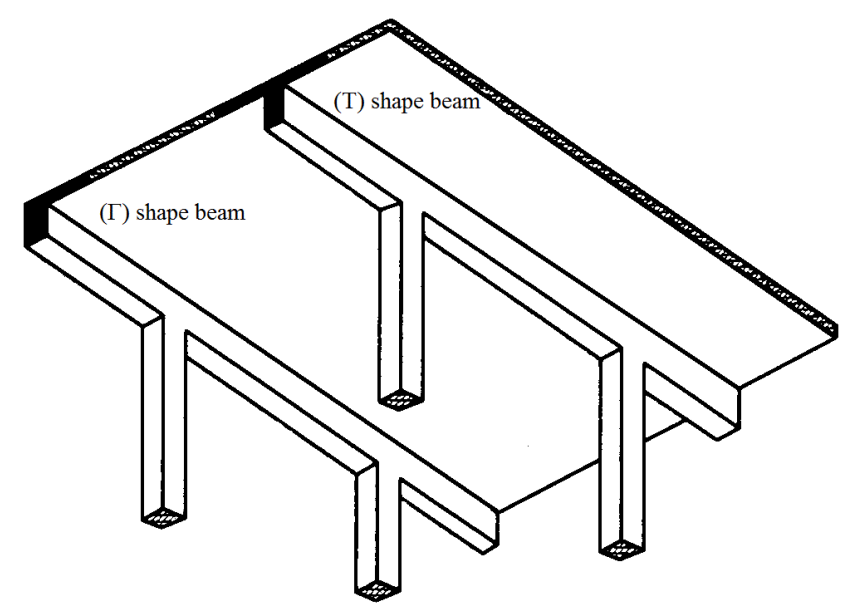

Fig. 1 Ribbed reinforced concrete slab supported on columns

Finite element method (FEM), which is implemented in most of currently used structural engineering softwares, allows to consider the real structural behaviour in the analysis [5-7]. Nowadays, structural engineers have a possibility to model almost all structures of analysed building in the same calculation model, which makes it possible to consider the overall structural behaviour and even the effect of non-uniform soil properties under different foundations. Nevertheless, in order to make the analysis simple and fast enough, various simplifications are still being adopted: usually, the internal forces are estimated assuming only the elastic behaviour of reinforced concrete structure, while the effect of reinforcement in the evaluation of internal forces is not taken into account. These and some other factors are considered only when the structural design of separate members is performed according to the previously estimated values of internal forces [8-11].

In this kind of internal forces analysis, the beams are modelled as one-dimensional Bar members, while for modelling of the slabs, two-dimensional Plate elements are used. In both cases, the elements are flat and aligned so that the bars would be located in the plane of the plates. The described way of modelling the structural members is convenient because the values of all internal forces (bending moments, axial and shear forces, torsional moment) are calculated and are easily applicable to further design of structural members. Meanwhile, when the analysed structure is modelled using volumetric elements, the results are presented in form of stresses instead of internal forces. Analysis of the results presented in the form of stresses and their application in detailed design of the particular members is more complicated. In addition, modelling and calculation of the structures consisting of Solid elements is a complex task, that requires considerably more resources. Consequently, in most cases engineers decide to use Bar and Plate elements for the structural analysis [12].

Simplification of the calculation model by using Bar and Plate elements also has a negative side. Since reinforcement of slab and beam members in ribbed reinforced concrete slab is joined, the beams act together with the slabs forming an integrated system: the ((T) shape cross-section beams and the slabs between them). When the ribbed RC slabs are modelled and calculated using Bar and Plate elements, the centroidal axes of the beam and the slab members are in the same level, therefore instead of (T) shape crosssection, (+) shape cross-section beams are used in FEM analysis. Despite having the same cross-sectional area as the (T) shape cross-section, other geometrical properties of the (+) shape cross-section ( $I$ is moment of inertia, etc.) are different. Thus, different bending stiffness values $E I$ of the beam members are obtained which change the distribution 
of the internal forces acting in continuous beams and the deflection of the beam members, as well as the deformation of the whole ribbed reinforced concrete slab. One of the possible ways to solve the described problem is an establishment of eccentricities in the structure. The centroidal axes of beam members can be moved lower simulating $(\mathrm{T})$ shape cross-section in calculation software's by using function "offset" [13]. However, this solution is not very practical for structural engineers. Application of the eccentricities creates additional axial forces that change the distribution of the internal forces in the beams and other structural members, therefore the design process of the analysed structure becomes considerably more complicated [14]. Another alternative approach to assess the described problem is to modify Young's modulus of concrete in the Bar members or to apply adjustment coefficients for moment of inertia. Nevertheless, the latter approach is also rather complicated for engineers due to the fact that design codes and engineering literature do not include any method describing what adjustment coefficients should be used and how their values should be estimated. General recommendations can be found on websites of design software's developers and in forums. In addition, various other ways of accurate beam members bending stiffness estimation can be found in the literature, yet all of them have positive and negative aspects [13-18]. The correct estimation of internal forces in the ribbed $\mathrm{RC}$ slabs and the accurate bending stiffness assessment are relevant topics discussed in various engineering forums and discussions [13-15].

In this paper a comprehensive explanation is presented on the calculation of moment of inertia $I$ adjustment coefficients that can be used for more precise calculations of internal forces acting in ribbed reinforced concrete slabs, when FEM design software's are used for the analysis. The presented calculation method is also applicable for other types of structures, such as basement walls, counterfort retaining walls, etc. Not only the derivation of moment of inertia $I$ adjustment coefficient, but also the comparative results of deflections and internal forces, estimated using the effective flange widths of $(\mathrm{T})$ shape cross-section beams which are specified in different design codes, are presented in this study. Deflections of beams calculated using discussed calculation approach (modelling ribbed slab from Bar and Plate elements) are compared with beam deflection results obtained from calculation model with Solid elements. Four differently loaded ribbed RC slabs with different geometrical properties were used for the comparative analysis. Moreover, the results were compared when different support conditions of the analysed slabs were taken into account. The comparative analysis results showed that moment of inertia adjustment coefficients equations, presented in this paper, give an opportunity for engineers to estimate internal forces in ribbed RC slabs simply and accurately enough by using FEM calculation software's. The derived equations are also applicable in cases when the span to depth ratio of the beams is small, where the shear deformation influences the total deflection significantly.

\section{Methods}

A single span monolithic ribbed reinforced concrete slab with equal spacing between five beams and the slab supported on top of the beams (Fig. 2) is analysed in order to investigate moment of inertia adjustment coefficients for beams.

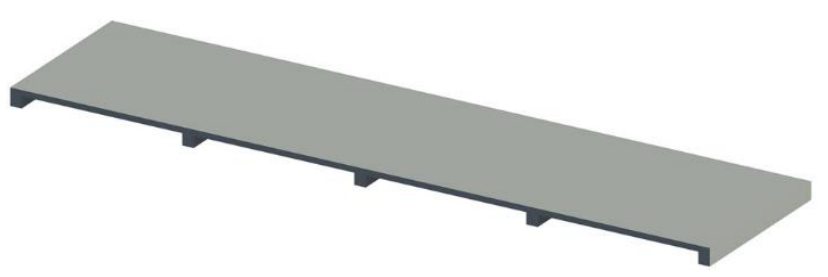

Fig. 2 3D model of analysed ribbed slab

To estimate moments of inertia values of the beam members it is needed to determine the effective flange widths of $(\mathrm{T})$ and $(+)$ shape cross-sections. Effective flange widths of the cross-sections have been calculated by using 4 different empirical methods. According to the first method, $b_{\text {eff }}$ values were chosen equal to slab widths which distribute acting loads to the particular analysed beam member (Fig. 3). The following three calculation methods are specified in RC structures design codes (STR [2], EC2 [3] and ACI [4]), which present different $b_{\text {eff }}$ calculation methods. More effective flange widths $b_{\text {eff }}$ calculation methods can be found in the literature $[19,20]$ aside from the mentioned methods that are compared in this paper.
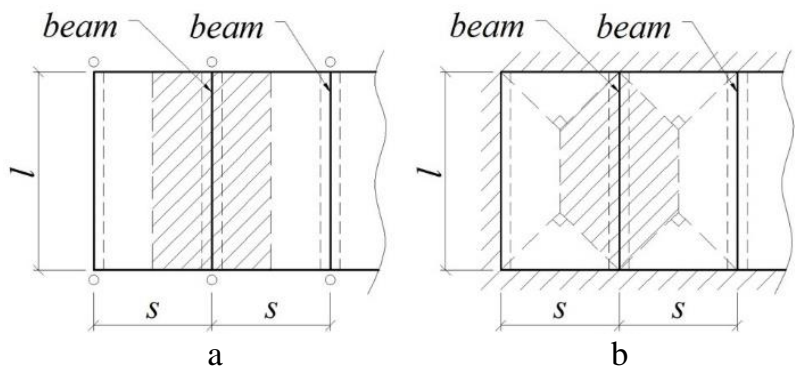

Fig. 3 Load distribution schemes (a-pinned supports, b - fixed supports)

It is first needed to calculate $(\mathrm{T})$ and $(+)$ shape cross-section (Fig. 4) moments of inertia by using equations of engineering mechanics in order to obtain moment of inertia adjustment coefficient. Moment of inertia of (T) shape cross-section beam in ribbed RC slab around its centroidal axis can be estimated using Eq. (1) [21, 22].

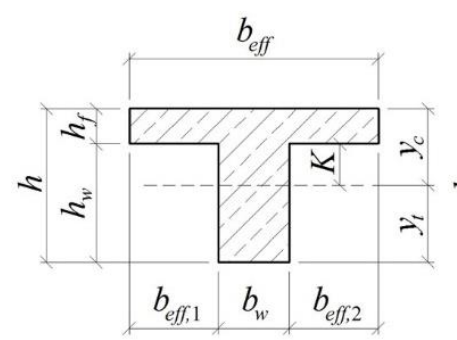

a

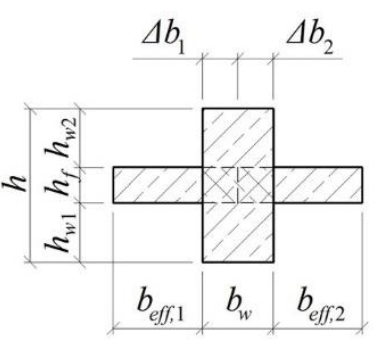

b
Fig. $4 \mathrm{a}-(\mathrm{T})$ shape cross-section, $\mathrm{b}-(+)$ shape cross-section; where: $K=h-y_{t}-h_{f}=y_{c}-h_{f}$

$$
\begin{aligned}
& I_{T}=\frac{b_{e f f} h_{f}^{3}}{12}+b_{e f f} h_{f}\left(h-\frac{h_{f}}{2}-y_{t}\right)^{2}+ \\
& +\frac{b_{w} h_{w}^{3}}{12}+b_{w} h_{w}\left(y_{t}-\frac{h_{w}}{2}\right)^{2},
\end{aligned}
$$


where: $I_{T}$ is $(\mathrm{T})$ cross-section moment of inertia; $b_{\text {eff }}$ is effective flange width $\left(b_{\text {eff }}=b_{\text {eff, }, 1}+b_{w}+b_{\text {eff, } 2}\right) ; h_{f}$ is flange depth; $b_{w}$ is web thickness; $h_{w}$ is web height; $y_{t}$ is distance from tensile edge to the centroid of cross-section.

The moment of inertia of (+) shape cross-section, which is created modelling ribbed slab from Bar/Plate elements in FEM softwares, can be calculated by using Eq. (2) (assuming that $k_{M}=1$ ):

$$
I_{+, \text {mod }}=k_{M} \frac{b_{w} h^{3}}{12}+\frac{b_{e f f, 1} h_{f}^{3}}{12}+\frac{b_{e f f, 2} h_{f}^{3}}{12}
$$

where: $I_{+, \text {mod }}$ is modified moment of inertia of $(+)$ shape cross-section corresponding to $(\mathrm{T})$ cross-section moment of inertia; $k_{M}$ is moment of inertia adjustment coefficient which takes into account the difference between $(+)$ and $(\mathrm{T})$ crosssection moment of inertia.

Hence, in order to model ribbed slab where beam members would have the same stiffness as the beams of the actual structure, the adjustment coefficient $k_{M}$ or $k_{M, V}$ of moment of inertia should be applied to the Bar part of (+) shape cross-section (web), so that the total moment of inertia of $(+)$ shape cross-section would be equal to $(\mathrm{T})$ shape crosssection moment of inertia $\left(I_{+, \bmod }=I_{T}\right)$. Coefficient $k_{M}$ should be used when the effect of shear deformations is not considered to deflection of the beams. Whereas, $k_{M, V}$ coefficient has to be used instead of $k_{M}$ when shear deformations should be taken into account.

When shear deformations are not considered, the moment of inertia adjustment coefficient $k_{M}$ can be calculated using Eq. (3) - i.e. by equating the right hand sides of Eq. (1) and Eq. (2) and solving for $k_{M}$.

$$
k_{M}=1+\frac{12 b_{w} h\left(y_{t}-\frac{h}{2}\right)^{2}+12\left(b_{\text {eff }, 1}+b_{\text {eff }, 2}\right) h_{f}\left(h-\frac{h_{f}}{2}-y_{t}\right)^{2}-\left(\Delta b_{1}+\Delta b_{2}\right) h_{f}^{3}}{b_{w} h^{3}},
$$

where: $\Delta b_{i}$ is half of web width because modelling with Bar and Plate elements results in duplication of cross-sections $(i=1,2)$. Note: With few small alterations Eq. (3) could be applied for cases where height of the beam is used without considering height of the slab (duplication of the slab and the beams does not exist) [15].

In the real structure, and also when the calculations are made using Solid elements, deflection of the beam members is influenced not only by flexural deformation, which is caused by bending moment, but also by shear deformation obtained from the acting shear forces. The latter one is significant when the span to depth ratio of the beams is small $(l / h \leq 10)$ [23]. The total deflection of the beams that consists of both flexural and shear deformations is expressed by Eq. (4) [24-26].

$$
\delta=\delta_{\text {bend }}+\delta_{\text {shear }}=\int_{l} \frac{M_{0} M}{E I_{T}} d x+\int_{l} \mu \frac{V_{0} V}{G A} d x,
$$

where: $\delta$ is the total (T) beam deflection; $\delta_{\text {bend }}$ is deflection component caused by bending moment; $\delta_{\text {shear }}$ is deflection component caused by shear deformations; $l$ is span of the beam; $E$ is modulus of elasticity of concrete; $G$ is shear modulus of concrete $(G \approx 0.4 E)$; $\mu$ is shear deformation coefficient dependant on the shape of cross-section; $M_{0}$ is bending moment due to unit load in the cross-section located in distance $z$ from the support; $M$ is bending moment due to external loads in the cross-section located in distance $z$ from the support; $V_{0}$ is shear force due to unit load in cross-section $z ; V$ is shear force caused by external loads in crosssection located in distance $z$ from the support; $A$ is the crosssectional area.

The total beam deflection in mid-span cross-section depends on the span length, the type of loads, bending stiffness of the beams and support conditions. Generally, when the beams of ribbed slab are loaded by uniformly distributed load, the total (T) beam deflection (Fig. 3, a) may be calculated using Eq. (5) [25]:

$$
\delta=k \frac{q l^{4}}{E I_{T}}+\mu \frac{q l^{2}}{8 G A},
$$

where: $q$ is line load on the primary beam (including the self-weight of the structure) $(\mathrm{kN} / \mathrm{m}) ; k$ is a coefficient dependant on the type of supports and load type $(k=1 / 384$, when supports are fixed; $k=5 / 384$, when supports are pinned; $k=2 / 384=1 / 192$, when one support is fixed and the other one is pinned).

When the effect of shear deformations is considered in the evaluation of beams deflections, it is needed to calculate the shear deformation coefficient $\mu$, which is used for the estimation of moment of inertia adjustment coefficient $k_{M, V}$. Value of shear deformation coefficient depends on the shape of cross-section. Calculation methods of the described coefficient can be found in the literature, i.e. "Shear Form Factors for Various Cross-Sections" [27] presents one. A non-linear variation of shear stresses in the beam cross-sections has to be considered since the intermediate $(\mathrm{T})$ shape cross-section and the edge $(\Gamma)$ shape crosssection beams are asymmetrical with respect to the horizontal axes, $[21,22]$. $(\Gamma)$ shape cross-section differs from $(\mathrm{T})$ shape cross-section by the fact that it has flange only on one side of the web, i.e. it contains only one of the two values $b_{\text {eff, } 1}$ or $b_{\text {eff,2 }}$ (Fig. 4). Thus, all analysed ribbed slabs consist of two $(\Gamma)$ shape cross-section beams (edge beams) and three $(\mathrm{T})$ cross-section beams (intermediate beams). Shear coefficients for various cross-sections can be estimated using empirical equations presented in the literature or calculated by FEM softwares [28]. For $(T)$ and $(\Gamma)$ shape crosssections used in the analysed ribbed slabs shear coefficients were calculated using Eq. (6) [27].

$$
\mu=\frac{A}{I_{T}^{2}}\left(x_{1}+x_{2}+x_{3}\right),
$$

where: $x_{1}, x_{2}$ and $x_{3}$ are coefficients for the calculation of shear coefficient expressed by Eq. (7) - Eq. (10). 


$$
x_{1}=\int_{-y_{t}}^{K} \frac{\left[b_{\text {eff }} h_{f}+(K-x) b_{w}\right]^{2}\left[\left(h-y_{t}\right)-\left[\frac{b_{\text {eff }} \frac{h_{f}^{2}}{2}+(K-x) b_{w} h_{f}+\frac{(K-x)^{2}}{2} b_{w}}{b_{e f f} h_{f}+(K-x) b_{w}}\right]\right]^{2}}{b_{w}} d x,
$$

where: $K=h-y_{t}-h_{f}$ (Fig. 4).

$$
x_{2}=\int_{K}^{h-y_{t}} \frac{\left(\left(h-y_{t}\right)^{2}-x^{2}\right)}{4} b_{e f f} d x .
$$

Calculation of coefficient $x_{3}$ is different for $(\mathrm{T})$ and ( $\Gamma)$ shape cross-sections. In case of $(\mathrm{T})$ cross-section $x_{3}$ may be calculated using Eq. (9):

$$
x_{3}=2 \int_{0}^{\frac{b_{e f f}}{2}} \frac{h_{f}^{2} x^{2}\left(h-y_{t}-\frac{h_{f}}{2}\right)^{2}}{h_{f}^{2}} h_{f} d x .
$$

For $(\Gamma)$ shape cross-sections Eq. (10) can be used to calculate $x_{3}$ coefficient:

$$
x_{3}=\int_{0}^{\frac{b_{w w}}{2}+b_{e f f, 2}} \frac{h_{f}^{2} x^{2}\left(h-y_{t}-\frac{h_{f}}{2}\right)^{2}}{h_{f}^{2}} h_{f} d x .
$$

Then, moment of inertia adjustment coefficient, considering the effect of shear deformations, can be estimated according to Eq. (11).

$$
k_{M, V}=\frac{\frac{12 I_{T} l^{2} A}{l^{2} A+k_{a} \mu I_{T}}-\left(b_{e f f, 1}+b_{e f f, 2}+\Delta b_{1}+\Delta b_{2}\right) h_{f}^{3}}{b_{w} h^{3}},
$$

where: $k_{a}$ is coefficient taking account of support conditions and the type of loading (in case of uniformly distributed load: $k_{a}=120$ - when supports are fixed; $k_{a}=24$ - when supports are pinned; $k_{a}=57.8$ - when one support is fixed and the other is pinned).

Simplified effective flange width $b_{\text {eff }}$ estimations of beams cross-sections according to STR [2], EC2 [3] and ACI [4] are presented bellow (Fig. 5 and Table 1).

Table 1

$b_{\text {eff }}$ calculation according to STR, EC2, ACI

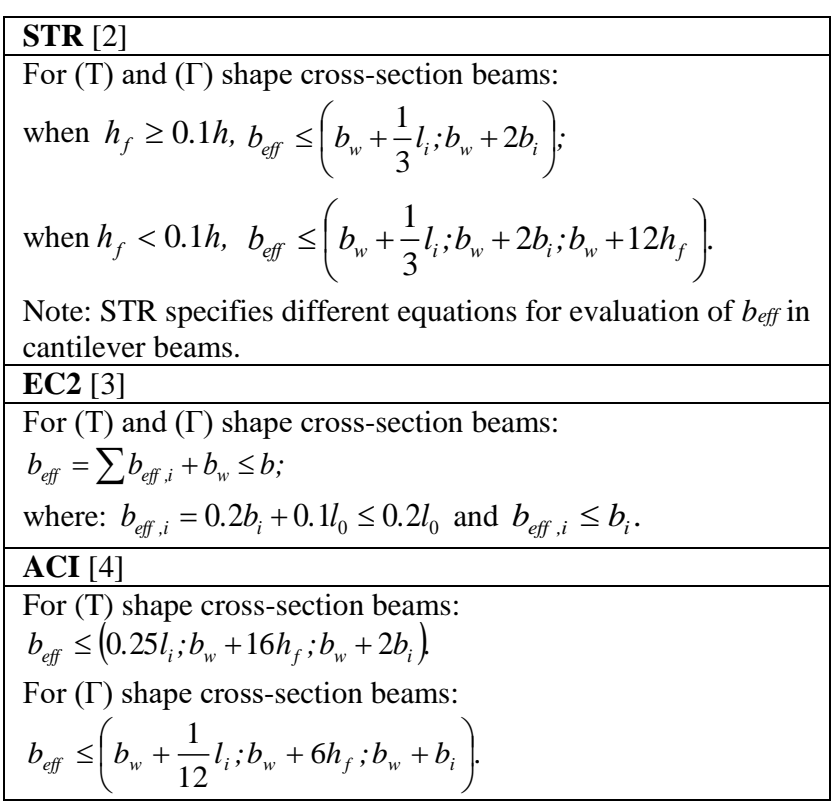

In $b_{\text {eff }}$ evaluation for beams with rigid supports $l_{0}$ was assumed to be equal to $0.7 l_{i}$. Whereas, $l_{0}$ value was assumed to be equal to span length of the beams $l_{i}$ when calculating $b_{\text {eff }}$ for beams with pinned supports.

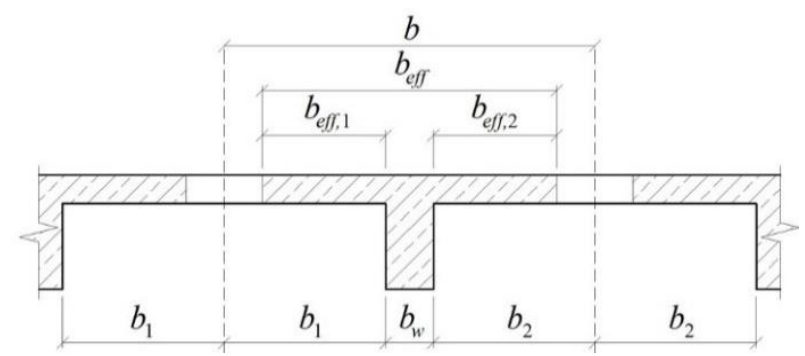

Fig. $5 b_{\text {eff }}$ calculation scheme

Four monolithic ribbed reinforced concrete slabs with different geometrical properties were analysed in order to perform previously mentioned calculations and to investigate the importance of moment of inertia adjustment coefficients. Schemes of the analysed slabs are illustrated in Figs. 6 and 7, while their geometrical properties are presented in Table 2.

Table 2

Geometrical properties of ribbed RC slabs

\begin{tabular}{|c|c|c|c|c|c|}
\hline Slab No. & $l, \mathrm{~m}$ & $s, \mathrm{~m}$ & $h, \mathrm{~m}$ & $b_{w}, \mathrm{~m}$ & $h_{f}, \mathrm{~m}$ \\
\hline 1 & 6.0 & 6.0 & 0.60 & 0.40 & 0.20 \\
\hline 2 & 10.0 & 6.0 & 1.00 & 0.40 & 0.20 \\
\hline 3 & 6.0 & 4.0 & 0.50 & 0.30 & 0.15 \\
\hline 4 & 4.0 & 4.0 & 0.40 & 0.20 & 0.15 \\
\hline
\end{tabular}

All ribbed slabs were loaded with identical $q=5 \mathrm{kN} / \mathrm{m}^{2}$ uniformly distributed area load in the analysis (self-weight was not considered separately). Deflections of beams obtained from calculation models using Bar and Plate elements were compared with deflections estimated from calculation models which are modelled from solid slab members. Slab elements in the volumetric slab models were divided into finite elements with size equal to $1 / 5$ web width of the beams (Fig. 8). 


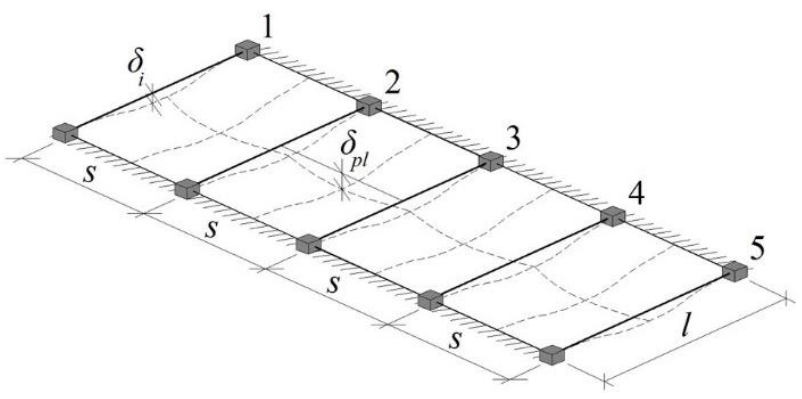

Fig. 6 Scheme of ribbed slab with fixed supports and deflections of beams and slab

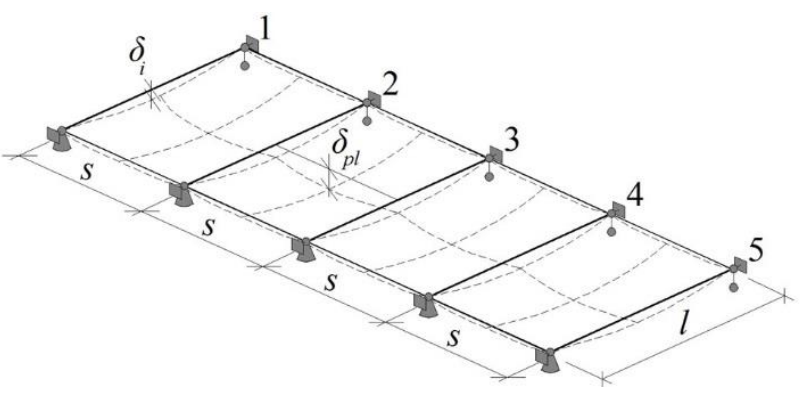

Fig. 7 Scheme of ribbed slab with pinned supports and deflections of beams and slab

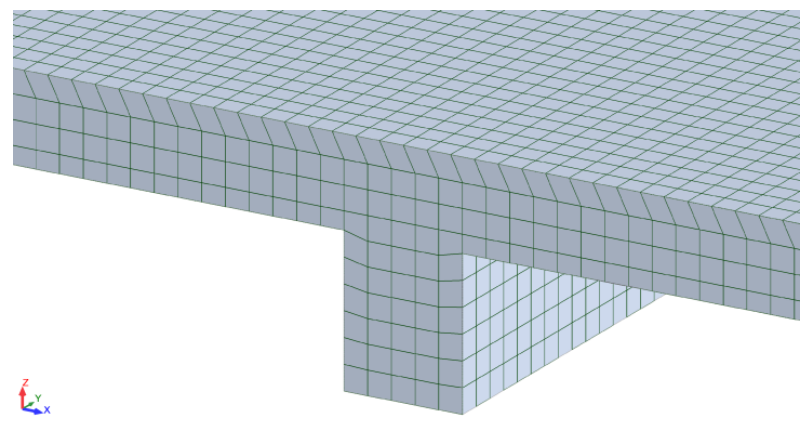

Fig. 8 Fragment of volumetric model of slab divided into finite elements (analysis performed using Robot Structural Analysis software [7])

In order to compare beam deflections, five different calculation models were created for each slab modelled using Bar and Plate elements that contained beams with the same cross-section but different bending stiffness. In the first case moment of inertia of beams were not modified (Fig. 9 notation NC). In the other calculation models moments of inertia of the beams were multiplied by moment of inertia adjustment coefficients which were evaluated assuming the effective flange widths equal to:

- $b_{\text {eff, } A L}=s$ for (T) shape cross-section beams and $b_{\text {eff, } A L}=s / 2+b_{w} / 2$ for $(\Gamma)$ shape cross-section beams (where: $s$ is the distance between the beams).

- $\quad b_{\text {eff,STR }}$ is calculated according to STR [2];

- $b_{\text {eff,EC2 }}$ is calculated according to EC2 [3].

- $b_{\text {eff, } A C I}$ is calculated according to ACI [4].

\section{Results}

The effective flange widths $b_{\text {eff }}$ were calculated according to the three different design codes discussed in this paper (Table. 1) in order to determine moment of inertia adjustment coefficients for the cross-sections of the analysed beams. All investigated ribbed RC slabs showed the same tendency of the effective flange widths $b_{\text {eff: }}$ : $b_{\text {eff, } A L}>b_{\text {eff,STR }}>b_{\text {eff,EC2}}>b_{\text {eff, } A C I}$. Every ribbed slab was calculated assuming fixed and pinned supports of the beams and the slabs (Figs. 6 and 7). In addition, all calculations were performed using $k_{M}$ and $k_{M, V}$ moment of inertia adjustment coefficients. The comparison of deflections and bending moments is illustrated in Figs. 9 and 10, while the notations used in the comparison of results (Figs. 9 and 10) are defined in Table 3.

Table 3

Notations used in Fig. 9 and 10

\begin{tabular}{|c|l|}
\hline Notation & \multicolumn{1}{c|}{ Definition } \\
\hline$\delta_{\text {bars }} / \delta_{\text {solids }}$ & $\begin{array}{l}\text { ratio of beams deflection calculated using Bar } \\
\text { model }(\delta \text { bars }) \text { and Solid model }\left(\delta_{\text {solids }}\right) .\end{array}$ \\
\hline$M_{k>1.0} / M_{k=1.0}$ & $\begin{array}{l}\text { ratio of maximum bending moments in the } \\
\text { beams using moment of inertia adjustment co- } \\
\text { efficient }\left(M_{k>1.0}\right) \text { and without modification } \\
\left(M_{k=1.0}\right) .\end{array}$ \\
\hline
\end{tabular}

Performed analysis of moment of inertia adjustment coefficients $k_{M}$ and $k_{M, V}$ indicated that lower values of coefficients are obtained when ribbed RC slab has fixed supports. It was noticed that in all cases the values of $k_{M, V}$ coefficients were estimated smaller than $k_{M}$ values. For $(\Gamma)$ shape cross-section beams, moment of inertia adjustment coefficient $k_{M}$ varied from 1.36 to 2.11 , whereas for (T) shape cross-section beams $k_{M}$ varied from 1.60 to 2.41 in the analysed ribbed RC slabs with fixed and pinned supports. In case of ribbed slabs with fixed supports $k_{M, V}$ values scattered in the range $0.57-1.26$ for $(\Gamma)$ shape cross-section beams, while $k_{M, V}$ values for $(\mathrm{T})$ shape cross-section beams varied between 0.79 and 1.42. Respectively, in slabs with pinned supports $k_{M, V}$ values varied from 1.28 to 1.74 for $(\Gamma)$ shape cross-section beams, and $k_{M, V}$ range was obtained from 1.50 to 2.05 for $(\mathrm{T})$ shape cross-section beams. It can be seen from the summarized results that in all cases shear deformations lead to smaller bending stiffness of the beams and greater deflections were estimated as the result. Fixed support conditions resulted the deflection component caused by bending moment being smaller in the total deflection (Eq. (4)), when deflection from shear deformations was constant.

Deflection ratios of beams in the analysed ribbed RC slabs, when calculations were performed using Bar/Plate elements and using Solid elements, are illustrated in Fig. 9. It can be seen from the presented comparative deflection results that application of moment of inertia adjustment coefficients $k_{M}$ and $k_{M, V}$ allows to estimate the deflections more accurately (deflections were obtained closer to the ones predicted by 3D calculation model)

As the result of analysis of all calculated beam deflections in the ribbed RC slabs modelled by using Bar/Plate and Solid elements, the observations are presented in a systematic way:

- Without application of moment of inertia adjustment coefficients $k_{M}$, and $k_{M, V}$ the deflections of beams in the calculation models consisting of Bar/Plate elements were higher in all cases compared to the 3D calculation models consisting of Solid elements. The deflections were higher by $15.2 \%-96.0 \%$ for $(\Gamma)$ shape cross-section beams, while for (T) shape cross-section beams, the estimated deflections were higher by $20.2 \%-98.0 \%$. Hence, in some configurations of slabs, the beams were almost twice slenderer than they should have been. 


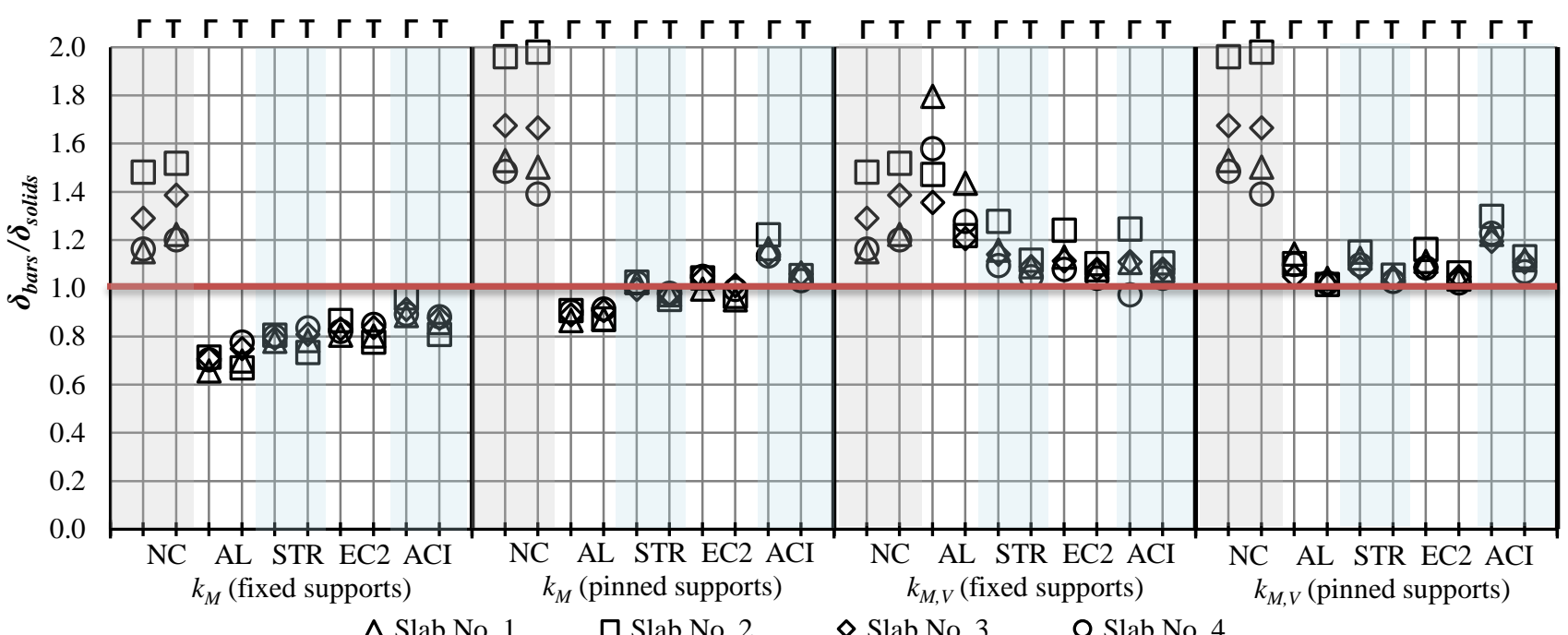

Fig. 9 Beams deflection comparison in ribbed RC slabs modelled using Bar/Plate elements and Solid elements. NC - beams without moment of inertia modification $\left(k_{M}=k_{M, V}=1.0\right)$; AL, STR, EC2 and ACI $-k_{M}$ and $k_{M, V}$ calculated using $b_{\text {eff }}$ values estimated according to load distribution width (Fig. 3), STR, EC2 and ACI methods respectively. ( $\Gamma$ ) shape cross-section beams (beam No. 1 in Figs. 6 and 7), (T) shape cross-section beams (beam No. 3 in Figs. 6 and 7)

Application of moment of inertia adjustment coefficients also provided relatively high differences in the beam deflections when the effective flange widths $b_{\text {eff }}$ were estimated according to the load distribution method. Beam deflections discrepancies varied from $-34.2 \%$ to $+79.7 \%$ for $(\Gamma)$ shape cross-section, while the differences in beams deflections were observed in the range from $-32.9 \%$ to $+43.7 \%$ for (T) shape cross-section. Here, "+" symbol indicates that deflection of the beams in the model consisting of Bar/Plate elements was calculated greater compared to calculation model with Solid elements, whereas "-" represents the opposite case. Thus, the deflection errors remain high enough and they are especially significant when $k_{M, V}$ coefficient is applied in cases of fixed support conditions.

- $\quad$ Significantly smaller discrepancies of beams deflections were noticed when moment of inertia adjustment coefficients were applied and the effective flange widths $b_{\text {eff }}$ were calculated according to any of STR, EC2 or ACI calculation methods. Comparative analysis showed that deflections discrepancies of $(\Gamma)$ shape cross-section beams varied between $-22.0 \%$ and $+26.7 \%$, while deviations of $(\mathrm{T})$ shape cross-section beams were obtained in the range of $-32.9 \%-$ $+26.7 \%$ when $b_{\text {eff }}$ values were estimated using calculation methods of the discussed design codes. Depending on slab configuration, support conditions and option to consider shear deformations, some calculation methods provided more accurate results than the others. However, the general tendency remained - application of moment of inertia adjustment coefficients $k_{M}$ ir $k_{M, V}$, calculated by using $b_{\text {eff }}$ values that were estimated according to the design codes discussed in this paper, lead to more accurate deflection values;

- $\quad$ The effect of shear deformations was more significant in cases of beams with fixed supports because in these cases the deflection component caused by bending moment was smaller in the total deflection and as a consequence, the deflection component caused by shear forces was more noticeable. Nevertheless, it is appropriate to use $k_{M}$ coefficient in most cases of ribbed slab design considering relatively small deflection differences and the complexity of $k_{M, V}$ coefficient calculation. It should be noted that application of $k_{M}$ instead of $k_{M, V}$ coefficient results in beam members having higher bending stiffness, which means greater values of estimated bending moments in the beams;

- Although the application of moment of inertia adjustment coefficients $k_{M}$ and $k_{M, V}$ does not provide a perfect match of deflections estimated from calculation models consisting of Bar/Plate elements and calculations performed by using Solid elements, it makes the calculations more accurate without overcomplicating the design. In addition, the application field of the proposed coefficient can be expanded by adding a possibility for the adjustment coefficient to consider the effect of cracking and creep of concrete to the bending stiffness of RC members.

Incorrect evaluation of beams (bar members) bending stiffness in the analysis of ribbed RC slabs leads not only to deflection inaccuracies but also it influences errors of the obtained internal forces in the beams. Underestimated bending stiffness of the beams results in lower bending moment values in those beams. The stiffness ratios of beams and plates have influence on the distribution of internal forces in plates as well. Other internal forces (e.g. shear forces) can also be redistributed because of inaccurate estimation of beams bending stiffness. Also, in addition to the redistribution of internal forces in ribbed slab, the possibility of internal forces redistribution arises in other structural elements.

Differences of bending moments in the analysed ribbed slabs caused by the application of moment of inertia adjustment coefficients are illustrated in Fig. 10.

Fig. 10 shows the relative difference of bending moments in the beams of ribbed RC slabs when moment of inertia adjustment coefficients $k_{M}$ and $k_{M, V}$ are applied considering $b_{\text {eff }}$ values obtained according to the calculation methods presented in Table 1.

It is evident from Fig. 9 that for $(\Gamma)$ shape crosssection beams with fixed supports the deflection results obtained using $k_{M}$ coefficient were most accurate when $b_{\text {eff }}$ were estimated according to the ACI calculation method. Fig. 10 shows that the bending moment values in the supports were obtained higher by $+1.0 \%-+6.8 \%$ when the mentioned $k_{M}$ coefficient was used compared to the bending 
moment values obtained without the consideration of the adjustment coefficient. Meanwhile, the application of $k_{M, V}$ coefficient, when $b_{\text {eff }}$ were estimated according to the EC2 method, increased the bending moment values in the supports in the range of $+0.3 \%-+2.2 \%$ compared to the calculations without the application of the adjustment coefficient.
The bending moment values increased in both cases but in the latter case, the deviation of $k_{M, V}$ coefficient lead to reduced moment of inertia, which consequently slightly increased the value of bending moment.

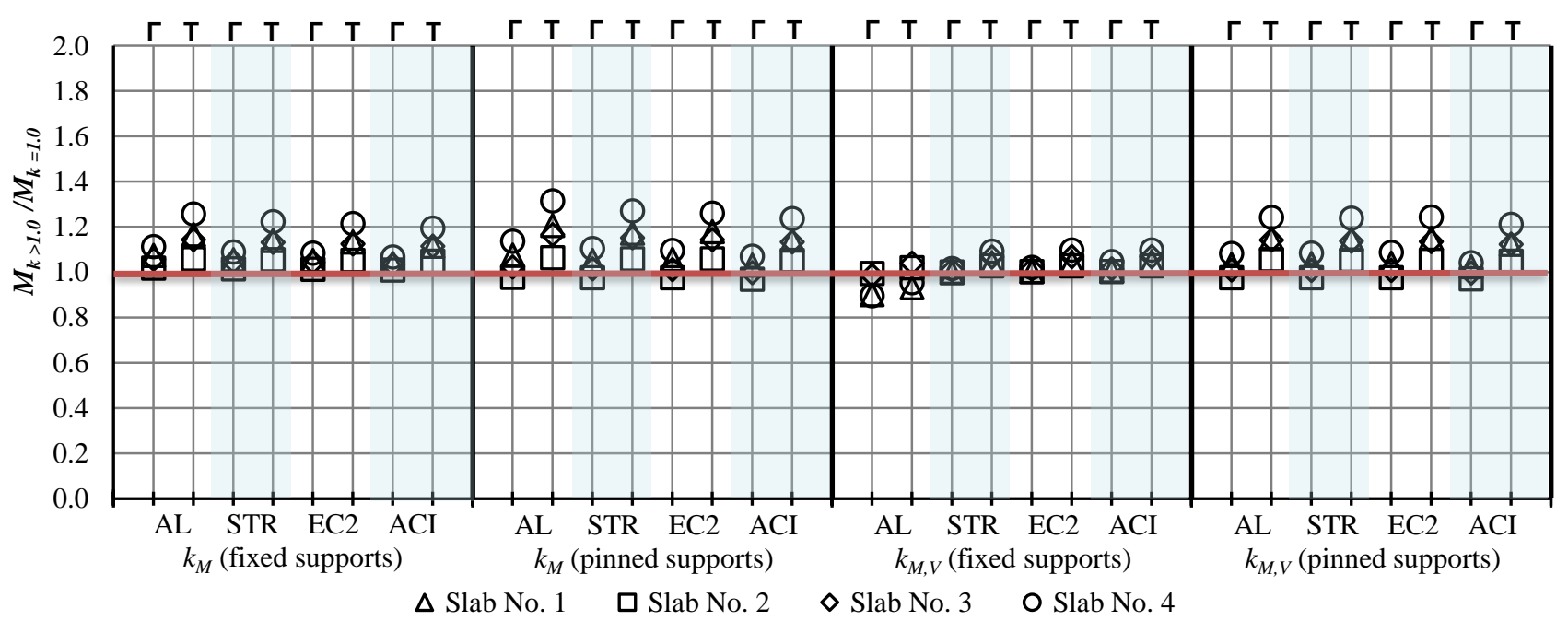

Fig. 10 Bending moments in beams of ribbed slabs dependence on moment of inertia adjustment coefficients $k_{M}$ and $k_{M, V}$

The analysis of $(\mathrm{T})$ shape cross-section beams with pinned supports indicated that deflection values were most accurate using $k_{M, V}$ coefficient when $b_{\text {eff }}$ were estimated according to the EC2 calculation method. It can be seen from Fig. 10 that when the described $k_{M}$ coefficient was used, the bending moment values in the supports were estimated higher by $+2.9 \%-+9.8 \%$ than without the consideration of the adjustment coefficient. Whereas, application of $k_{M}$ coefficient increased the bending moments in the supports in the range of $+5.0 \%-+19.5 \%$ when $b_{\text {eff }}$ values were evaluated according to the ACI method. The difference of results clearly shows that inaccurate determination of beams bending stiffness has a significant effect on the bending moments acting in those beams. Thus, a simpler and a more conservative solution by the application of $k_{M}$ adjustment coefficients influences a slightly higher amount of reinforcement in the designed beams.

When pinned supports were used (Fig. 9), deflections of $(\Gamma)$ shape cross-section beams were the most accurate with the application of $k_{M}$ coefficient when $b_{\text {eff }}$ were estimated according to the STR calculation method. Fig. 10 shows that when $k_{M}$ adjustment coefficient was applied, the bending moment in the beam mid-span section varied between $-2.4 \%$ and $+10.4 \%$ compared to the bending moment values without an adaptation of the adjustment coefficient. Deflections of (T) shape cross-section beams coincided the best with the results of 3D calculation model when $k_{M}$ coefficient was calculated using $b_{\text {eff }}$ values estimated according to the calculation method presented in STR. It can be seen from Fig. 10 that the application of the mentioned $k_{M}$ coefficient increased the bending moments in the mid-span section in the range of $+5.9 \%-+27.2 \%$. These results again confirmed the influence of beams bending stiffness on the bending moment values in those beams. Whenever plastic hinges are not considered, such increase of the bending moments can lead to the necessity of reinforcement amount recalculation or even the need of different cross-section. The outcome of underestimation of bending stiffness differences due to $(+)$ shape cross-section existence instead of $(\mathrm{T})$ shape cross-section might even lead to unsafe design of the structure.

Bending stiffness of beams also has an influence on the values of shear forces. In the case illustrated in Fig. 7 the differences of shear forces were not large when the presented equations were used for the calculation of moment of inertia adjustment coefficients $k_{M}$ and $k_{M, V}\left(b_{\text {eff }}\right.$ were estimated according to STR, EC2 and ACI methods). The average difference of shear forces was close to $0 \%$ (range of variation from $-2.6 \%$ to $+2.2 \%$ ). However, in the case illustrated in Fig. 6 the bending stiffness of beams had a greater effect to the differences of shear forces in the beam members. Shear forces varied in the range of $-0.1 \%-+17.8 \%$ in $(\Gamma)$ and $(\mathrm{T})$ shape cross-section beams calculated with the adaptation of the adjustment coefficients $k_{M}$ and $k_{M, V}$ that were calculated using equations presented in the paper (when $b_{\text {eff }}$ were evaluated according to STR, EC2 and ACI calculation methods). Hence, depending on the structural scheme of ribbed RC slab, incorrect evaluation of beams bending stiffness can result not only insufficient amount of longitudinal but also transversal reinforcement.

Incorrect evaluation of $(\Gamma)$ and $(\mathrm{T})$ shape cross-section beams bending stiffness also changes the values of internal forces in the slab members. Underestimated bending stiffness of the beams determines unreasonably high deflections, and consequently the bending moment values change both - in the supports and in the mid-span section. In the results analysis the bending moments of the slab members illustrated in Figs. 6 and 7 in their support regions above the beam members when $k_{M}$ coefficients were applied ( $b_{\text {eff }}$ assumed according to the EC2 method) were compared with the bending moments obtained without using adjustment coefficients. Application of $k_{M}$ coefficients increased the bending moments of the slab members in the support regions above the beams by $+10 \% \ldots+40.9 \%$ in cases of the ribbed $\mathrm{RC}$ slabs analysed in this paper. The analysis of ribbed RC slabs showed that the bending moments in the supports of 
the slab members are considerably underestimated when moment of inertia adjustment coefficients are not used, which consequently might lead to insufficient amount of the designed slab reinforcement above the beam members. Besides, the comparison of the bending moment values in midspan regions of the slab members in the ribbed RC slabs illustrated in Fig. 6 showed that the application of $k_{M}$ coefficients (when $b_{\text {eff }}$ values were determined according to the EC2 method) increased the bending moments in the range from $+1.8 \%$ to $+10.6 \%$. Whereas, the bending moments reduced from $-12.8 \%$ to $-8.3 \%$ in the case of the slabs presented in Fig. 7.

Concluding the comparative analysis, it is evident that bending stiffness of $(\Gamma)$ and $(\mathrm{T})$ shape cross-section beams has a significant impact not only to the deflections but also to the internal forces in all members of the ribbed slab structure. Therefore, the consideration of moment of inertia adjustment coefficients $k_{M}$ and $k_{M, V}$ proposed in this paper makes the design process of ribbed reinforced concrete slabs more accurate without overcomplicating it. The proposed adjustment coefficients can also be used as a simplification for accurate evaluation of internal forces without using "offset" function or other calculation methods, or without application of Solid elements.

\section{Conclusions}

In this paper, derivation and equations for calculating moment of inertia adjustment coefficients $k_{M}$ and $k_{M, V}$ are presented. Application of coefficient $k_{M}$ includes only the consideration of difference between $(+)$ and $(\mathrm{T})$ shape crosssections moments of inertia, while $k_{M, V}$ coefficient also allows to evaluate the effect of shear deformations. The equations presented in this paper allow to evaluate the actual bending stiffness of $(\Gamma)$ and $(\mathrm{T})$ shape beams cross-sections simply enough when estimating the internal forces in ribbed reinforced concrete slabs.

Comparative analysis of 4 ribbed slabs with different geometrical properties and support conditions modelled using Bar/Plate elements and Solid elements indicated that it is appropriate to use effective flange widths $b_{\text {eff }}$ calculation method presented in STR, EC2 and ACI design codes for the evaluation of $k_{M}$ and $k_{M, V}$ adjustment coefficients. Adaptation of these calculation methods for the analysis of edge beams $(\Gamma)$ cross-sections proposed $k_{M}$ values in the range from 1.335 to 1.865 and $k_{M, V}$ values between 0.994 and 1.655. Whereas, $k_{M}$ values obtained for intermediate beams (T) cross-sections varied from 1.601 to 2.192 , while $k_{M, V}$ values varied in the range $1.172-1.973$. When these $k_{M}$ and $k_{M, V}$ coefficients were used, deflections of the beam members in ribbed RC slab modelled using Bar/Plate elements varied from $-26.7 \%$ to $+29.9 \%$ depending on the case and shape of cross-section compared to deflection values predicted by analysis of the slabs consisting of Solid elements. Application of $k_{M}$ coefficient resulted the difference of bending moments from $-3.0 \%$ to $+27.2 \%$ and the difference of shear forces in the range between -2.6 and $+17.8 \%$ in $(\Gamma)$ and $(\mathrm{T})$ shape cross-section beams (here "+" indicates the increase) compared to the estimated values of bending moments and shear forces when the adjustment coefficients were not used. Whereas, $k_{M, V}$ coefficient changed the bending moment values in the range of $-2.9 \%-+24.4 \%$ and the shear forces in the range from $-2.4 \%$ to $-7.9 \%$. Comparative analysis of the calculated ribbed slabs also showed that more accurate evaluation of $(\Gamma)$ and $(\mathrm{T})$ shape beams bending stiffness changed the values of bending moments in slab members in the range between $-12.8 \%$ and $+40.9 \%$.

The adaptation of the proposed adjustment coefficients in structural engineering softwares is simple enough and it allows to estimate the real geometry of ribbed RC slabs modelled with Bar/Plate elements accurately. Consideration of the real slab geometry by analysed method leads to more accurate estimation of internal forces in all structural members, as well as allows to perform further design simpler and more accurately.

\section{References}

1. Gambhir, M.L. 2011. Design of Reinforced Concrete structures. New Delhi: PHI Learning Private Limited. $740 \mathrm{p}$.

2. STR 2.05.05:2005. Design of concrete and reinforced concrete structures: Building technical regulation. Vilnius: Environment Ministry of Lithuanian Republic, 123 p. (in Lithuanian).

3. EN 1992-1-1:2004. Eurocode 2: Design of concrete structures. Part 1-1. General rules and rules for buildings. European Committee for Standardization (CEN), 2004, $225 \mathrm{p}$.

4. ACI committee 318. Building code requirements for structural concrete (ACI 318-14): an ACI Standard. Commentary on building code requirements for structural concrete (ACI 318R-14) / reported by ACI committee 318. Farmington Hills, MI: American Concrete Institute, 2015, $519 \mathrm{p}$.

5. DLUBAL: Structural Engineering Software for Analysis and Design. [Online]. 2018. [Viewed 8 December 2018]. Available from: https://www.dlubal.com/en

6. SCIA a Nemetscheck Company: Structural Analysis \& Design with SCIA Engineer. [Online]. 2018. [Viewed 8 December 2018]. Available from: https://www.scia.net/en/software/scia-engineer

7. AUTODESK: Robot Structural Analysis Professional features. [Online]. 2018. [Viewed 8 December 2018]. Available from:

https://www.autodesk.com/products/robot-structuralanalysis/overview

8. Chanakya, A. 2009. Design of Structural Elements: Concrete, Steelwork, Masonry and Timber Design to British Standards and Eurocodes. 3rd ed. London, New York: Spon Press. 502 p.

9. Wight, J. K.; McGregor, J. G. 2012. Reinforced Concrete: Mechanics and Design. 6th ed. Harlow: Pearson Education. 1175 p.

10. Valivonis J.; Šneideris A. 2007. Reinforced concrete ribbed in-place floors. Book. Vilnius: Technika. 133 p. (in Lithuanian).

11. Mosley, W. H.; Bungey, J.; Hulse, R. 2012. Reinforced Concrete Design: to Eurocode 2. 7th ed. Basingstoke: Palgrave Macmillan. 448 p.

12. Waia, C. M.; Rivai, A.; Bapokutty, O. 2013. Modelling optimization involving different types of elements in finite element analysis. IOP Conf. Series: Materials Science and Engineering 50(1) 1-8. http://dx.doi.org/10.1088/1757-899X/50/1/012036.

13. AUTODESK: Beam offsets [Online]. 2012. [Viewed 8 December 2018]. Available from: 
https://forums.autodesk.com/t5/robot-structural-analysis-forum/beam-offsets/m-p/3332921.

14. AUTODESK: How to design reinforcement for RC T slab (T beam) in Robot? [Online]. 2011. [Viewed 8 December 2018]. Available from:

http://forums.autodesk.com/t5/robot-structural-analysis-forum/t-slab/m-p/3185418\#M915.

15. AUTODESK: Beam / slab interaction [Online]. 2016. [Viewed 8 December 2018]. Available from: https://forums.autodesk.com/t5/robot-structural-analysis-forum/beam-slab-interaction/td-p/6685053.

16. DLUBAL: Downstand Beams, Ribs, T-Beams: Modeling and Determination of Internal Forces. [Online]. 2018. [Viewed 8 December 2018]. Available from: https://www.dlubal.com/en/support-and-learning/support/knowledge-base/001411.

17. SCIA a Nemetscheck Company: Why is there an axial force in the rib? [Online]. 2018. [Viewed 8 December 2018]. Available from:

https://www.scia.net/en/support/faq/tips-and-tricksresults/why-there-axial-force-rib.

18. Bentley Communities: Waffle / Ribbed Slabs in STAAD.Pro. [Online]. 2018. [Viewed 8 December 2018]. Available from:

https://communities.bentley.com/products/ramstaad/f/ram-staad-forum/137872/waffle-ribbed-slabsin-staad-pro.

19. Ciesielczyk, K.; Szumigała, M.; Ścigałło, J. 2017. The numerical analysis of the effective flange width in T-section reinforced concrete beams. Procedia Engineering 172: 178-185. http://dx.doi.org/10.1016/j.proeng.2017.02.047.

20. Küçükarslan, S. 2010. A Finite Element Study on the Effective Width of Flanged Sections: Master thesis. Middle East Technical University, Ankara. 63 p.

21. Gere, J. M.; Goodno, B. M. 2013. Mechanics of Materials. 8th ed., SI ed. Stamford: Cengage learning. $1098 \mathrm{p}$.

22. Čižas A. 1993. Materials mechanics: mechanics of structural elements. Textbook for students of technical science. Vilnius: Technika. 408 p. (in Lithuanian).

23. Fertis, D. G. 1996. Advanced Mechanics of Structures. 1st. ed. New York: CRC Press. 512 p.

24. Kargaudas V. 2011. Basis of structural mechanics. Book. Kaunas: Publishing house of Vilnius pedagogical University. 228 p. (in Lithuanian).

25. Skaggs, T. D. 1992. Shear Deflection of Composite Wood Beams: Master thesis. Texas A\&M University, Texas. 93 p.

26. Skaggs, T. D.; Bender, D. A. 1992. Shear deflection of composite wood beams. Wood and Fiber Science 27(3): 327-338.

27. Rezayekhadjavi, H. 1979. Shear Form Factors for Various Cross-Sections. Major technical report. Montreal. 82 p.
28. Iyer, H. 2005. The Effect of Shear Deformation in Rectangular and Wide Flange Sections: Master thesis. State University, Blacksburg, Virginia. 112 p.

Š. Kelpša, G. Rinkevičius, T. Zingaila, M. Augonis, V. Kitovas

\section{COEFFICIENT OF MOMENT OF INERTIA FOR RIBBED RC SLAB BEAMS}

S u m m a r y

During the design process of monolithic ribbed slabs, engineers face a common issue how to correctly evaluate stiffness of the beams. When Bar and Plate elements are used for analysis of the slabs, the neutral axis of those members are in the same level, therefore the stiffness of (T) shape cross-section is not considered correctly in the calculations. In this case the internal forces are obtained incorrectly as well as deflections of the beams are overestimated. A simple method is discussed in this paper, which allows engineers to calculate internal forces and deformations of mentioned type slabs more accurately with FEM programs by using Bar and Plate elements. The method is based on Bar elements moment of inertia adjustment.

After the comparative analysis of differences between moment of inertia of $(\mathrm{T})$ and $(+)$ shape cross-sections as well as deflection discrepancies, the adjustment coefficient expression is presented. In order to reflect the actual behaviour of ribbed slabs even more accurately the influence of shear deformations is also considered. In this case not only the member geometry but the material properties, loading scheme and even supports are taken into account in the calculations of the adjustment coefficient. Selection of the most appropriate (effective) flange width of (T) shape cross-section is also analysed in this paper. Comparative calculations were done using different effective flange widths $b_{\text {eff }}$ calculated by EC2 (Eurocode 2), "STR" (Lithuanian Construction Technical Regulations) and ACI (American Concrete Institute) methods. In order to assess the reliability of the proposed calculation method and the calculation results all plates were also analysed using Solid elements.

Application of the presented expressions of moment of inertia coefficient will allow engineers to evaluate stiffness of $(\Gamma)$ and $(\mathrm{T})$ shape cross section beams simply, fast and accurately enough for most of structural engineering calculations.

Keywords: Ribbed reinforced concrete slabs, stiffness, moment of inertia, T beams, FEM, structural engineering calculations, design.

Received February 04, 2019 Accepted June 14, 2019 